Journal of Patient-Centered

$4-27-2020$

\title{
Challenges of Pediatric Disease in Adulthood
}

Dennis J. Baumgardner

Brian Chicoine

Follow this and additional works at: https://aah.org/jpcrr

Part of the Congenital, Hereditary, and Neonatal Diseases and Abnormalities Commons, Family Medicine Commons, Mental and Social Health Commons, Other Medical Sciences Commons, Pediatrics Commons, and the Primary Care Commons

\section{Recommended Citation}

Baumgardner DJ, Chicoine B. Challenges of pediatric disease in adulthood. J Patient Cent Res Rev. 2020;7:142-6. doi: 10.17294/2330-0698.1756

Published quarterly by Midwest-based health system Advocate Aurora Health and indexed in PubMed Central, the Journal of Patient-Centered Research and Reviews (JPCRR) is an open access, peer-reviewed medical journal focused on disseminating scholarly works devoted to improving patient-centered care practices, health outcomes, and the patient experience. 


\title{
EDITORIAL
}

\section{Challenges of Pediatric Disease in Adulthood}

\author{
Dennis J. Baumgardner, MD, ${ }^{1}$ Brian Chicoine, $\mathrm{MD}^{2,3}$ \\ ${ }^{1}$ Department of Family Medicine, Aurora UW Medical Group, Aurora Health Care, Milwaukee, WI; ${ }^{2}$ Adult Down \\ Syndrome Center, Advocate Medical Group, Park Ridge, IL; ${ }^{3}$ Family Medicine, Advocate Lutheran General Hospital, \\ Park Ridge, IL
}

$\mathrm{E}$ lsewhere in this issue of the Journal of PatientCentered Research and Reviews, Doyle and colleagues explore functional outcomes and lived experiences of adults with X-linked hypophosphatemia. ${ }^{1}$ This entity, generally diagnosed in the pediatric age group, progresses in adulthood with increasing pain and disability. The study authors identified 3 primary themes common to their patient population: presence of chronic pain, fear of falling, and perception of lack of clinician credence given to patient concerns. ${ }^{1}$ The traits of resistance, adaptability, and compensation among patients with X-linked hypophosphatemia also were noted. ${ }^{1}$

We have previously reported on the issue of transitions of care from the pediatric to the adult clinical world among patients with significant childhood-onset disease. $^{2}$ That focused review explored the current status of such health care transitions, the logistics and pitfalls of these transitions, and measures that practices and health care systems could take to ensure more effective care. ${ }^{2}$ This commentary further discusses the medical pitfalls and psychosocial issues surrounding childhood-onset disease in adult survivors once transition has taken place.

There are many well-described childhood-onset diseases that remain problematic for adults and cause significant physical and psychological morbidity type 1 diabetes mellitus, ${ }^{3}$ sickle cell disease, ${ }^{4}$ autism, ${ }^{5}$ and pediatric age-onset liver disease, ${ }^{6}$ to name a few.

Correspondence: Dennis J. Baumgardner, MD, Aurora Sinai Medical Center, 1020 N. 12th St., \#4180, Milwaukee, WI 53233 (dennis.baumgardner@aurora.org)
In this editorial, 4 other known medical and surgical conditions have been chosen as examples to illustrate the issues often faced by adults with childhood-onset disease. In all cases, the transition from pediatric to adult care has the potential to produce (at least transiently) lower physical and psychological wellbeing than at pretransition, and issues may vary by gender and the specific medical condition. ${ }^{7}$ Certainly, very individualized experiences of transition are to be anticipated.

\section{Down Syndrome}

We will discuss and primarily focus on Down syndrome (DS) as a prototype condition in this regard. In the past, individuals with DS less frequently lived into adulthood, but that number has increased significantly since the early 1980s, when life expectancy was about 25 years, to about 60 years now. ${ }^{8-10}$ People with Down syndrome often have difficulty finding health care providers who can or will provide services for adults. The reasons include: 1) concerns regarding inadequate insurance reimbursement (particularly Medicaid), which may be particularly problematic due to longer time often needed for appointments; and 2) clinician's lack of knowledge, as there is often insufficient training in caring for adults with DS in medical school and residency. ${ }^{\text {cf. } 11}$ An additional challenge for adults with DS is finding a provider who will communicate directly with the individual with DS and will include them (to the level of the patient's capability) in health care decision-making.

Particular medical issues facing adults with DS can be placed broadly (with some overlap) into 3 categories: DS-associated diseases that occur in childhood or adolescence and persist into adulthood; DS-associated diseases that tend to first manifest in adulthood; 
and common adult comorbidities that may arise independent of, or are partially associated with, DS (diabetes mellitus, dyslipidemia, etc)..$^{8,9,12}$

Congenital heart disease (CHD) is one example in the first category. Approximately half of patients with DS have CHD, most commonly endocardial cushion and ventricular septal defects. ${ }^{12,13}$ Many of these defects are repaired prior to adulthood; however, patients with DS are at higher risk of acquired valvular and other heart disease, which may not manifest until adulthood. ${ }^{12}$ There is a higher risk of embolic (presumed to be related to congenital heart disease) and hemorrhagic stroke in adults with DS. ${ }^{14}$ Similarly, orthopedic problems, and the much less common congenital defects of the gastrointestinal tract, also may be discovered and repaired prior to adulthood; celiac disease has a higher prevalence in DS and may first become recognized in adulthood. . $^{8,912,13}$

Constipation, obesity, hearing loss, and diseases from narrowed otolaryngologic passage (ie, congestion, cerumenosis, obstructive sleep apnea) as well as immune system, hematologic, and ophthalmologic problems are examples of issues that typically carry across the life span. ${ }^{8,9,12,13,15,16}$ Seizures in DS have a trimodal distribution, with the second peak occurring after puberty. ${ }^{9}$ Thyroid disease (most typically hypothyroidism) and osteopenia/osteoporosis may first manifest in those with DS in childhood or adulthood. ${ }^{8,9,12}$

A common example in the second category of medical issues is development of dementia. One community survey revealed that dementia was associated with mortality in the majority $(70 \%)$ of older adults with DS. ${ }^{17}$ Virtually all patients with DS will manifest neuropathological changes consistent with Alzheimer's disease, and most will manifest clinical/ symptomatic Alzheimer's in older age, typically well before the median age of onset in the general adult population. ${ }^{18,19}$ The diagnosis of Alzheimer's dementia may be difficult in this population due to baseline cognitive and behavioral function or clinical ascertainment of baseline functioning. The ability of the primary care clinician to follow patients with DS over a long period of time is helpful in the latter regard. ${ }^{18}$ Much investigative work remains to be done regarding useful tests for early diagnosis, prevention, and treatment. ${ }^{18,20}$
There are gaps in our knowledge about most cooccurring conditions in adults with DS. Many cooccurring conditions have a different incidence profile. This can lead to over- and underdiagnosis. In addition, we do not have clear direction on how we should alter screening and prevention recommendations. Atherosclerosis is very uncommon, for example, as are solid tumors. ${ }^{8}, 14$ Should we be screening for certain cancers (eg, colonoscopy, mammogram) or treating patients with statins to lower the risk of myocardial infarctions (that are uncommon)? $?^{8,21}$ Other conditions are more common - what are screening implications for Alzheimer's, sleep apnea, thyroid disease and others? There are also gaps in our knowledge in how best to include people with DS in their own health promotion. The problem is not that people with DS cannot learn how to participate in promoting their health (most individuals can), the problem is that we have not figured out the best ways to include them in the process.

Particular pitfalls to avoid for clinicians taking care of adult patients with DS include missing physical, sexual, or psychological abuse, failure to provide routine adult preventive care, overevaluation or overtreatment of minor hematologic and other laboratory "abnormalities" that may be typical of DS, delayed diagnosis of emerging disorders such as sleep apnea, leukemia, and early onset Alzheimer's, and failure to address palliative and end-of-life care at the appropriate time. . $^{8,915,22}$

A significant problem faced by adults with DS is the lack of understanding by providers of the interaction between mental and physical health. ${ }^{23,24}$ Particularly when the individual has limited verbal skills, the likelihood that the presentation of the physical problem will be wholly or partially behavioral in etiology or the result of a change in their mental health is significant. This lack of knowledge may lead to inadequate or inaccurate treatment, often overdiagnosis of mental health problems without appreciation of the contribution of physical health. Some psychiatric-like presentations are manifestations of acute regression, which may be triggered by a significant emotional stress. ${ }^{24,25}$ Similarly, there is overdiagnosis of mental health problems due to the lack of understanding of common characteristics of people with DS. For example, a very high percentage of people with DS talk 
to themselves ("self-talk"). This is often misinterpreted as psychoses and can lead to overtreatment. ${ }^{23,26}$

Social issues are significant, and the following examples only scratch the surface. For many children with DS who transition to adulthood and graduate from the school system, there are significant challenges in finding employment and meaningful activity. ${ }^{27}$ Finding appropriate residential opportunities is also a significant challenge for many. These have significant implications for physical and mental health. In older adults, the earlier onset of some health conditions, particularly Alzheimer's, presents additional challenges. This is often complicated by the primary caregiver being an aging parent(s). Both authors of this editorial have observed the unique situation for siblings in which both the parent and the sibling with DS develop Alzheimer's at the same time.

\section{Cystic Fibrosis}

In developed countries, the majority of patients with cystic fibrosis (CF) live into adulthood. ${ }^{28,29}$ This has resulted in the need for infrastructure to ensure a workforce of respiratory care clinicians and support staff who are adequately trained in the management of $\mathrm{CF}$ in adults. ${ }^{28,29}$ Primary care clinics also need to be attuned to the nuances of care for this population ${ }^{29}$ and where to best access referral services, including lung transplant teams, if needed.

Medically, major life-threatening presentations in adult patients with CF include respiratory infections, pneumothorax, respiratory failure, and gross hemoptysis. ${ }^{28}$ Nonthreatening but important issues include the potential for additional morbidity (eg, diabetes), substance abuse, liver disease, and other adult medical problems. ${ }^{28}$ Some clinical paradigms are changing with regard to adult $\mathrm{CF}$ care; for example, a decline in the prevalence of traditional $\mathrm{CF}$ airway pathogens has been observed. ${ }^{30}$

Major psychosocial issues facing adults with $\mathrm{CF}$ include having normal family and friend relationships, employment barriers (including the need for additional time to complete assignments and illness-day accommodations), coping with complex medical needs and treatments, depression, anxiety, and uncertainty and distress regarding early death. ${ }^{28,31}$ Other issues cross over between the psychosocial and the medical realm, including concealment of disease, reproductive challenges, and adherence to treatment. ${ }^{28,31}$ Screening for and attention to socially complex young adults with CF at the time of transition to adult care may result in fewer avoidable hospitalizations. $^{32}$

Fortunately, in the case of $\mathrm{CF}$, there are now many facilities for adult CF care in the United States, and transition from pediatric providers generally occurs without significant gaps in care. ${ }^{33}$ That said, major complications and premature death remain prevalent. Attention must be paid to proper palliative and end-oflife care. ${ }^{28,34}$

\section{Congenital Heart Disease}

Once associated with a grim prognosis, most patients with CHD undergo successful neonatal cardiac surgery and survive into adulthood. ${ }^{35,36}$ One author made the point that these individuals "are not 'cured' and almost all require lifelong cardiac care." 35 While limited adult life span may be a central issue for patients with $\mathrm{CF}$, some adults with CHD also still deal with "threatened futures." ${ }^{31}$ Like all examples discussed in this editorial, a primary care medical home and coordination with specialists is paramount for CHD management, and issues of lifestyle, prevention, and psychosocial care remain important. ${ }^{2,31,35}$

Significant medical/surgical issues remain for many adults with CHD, including risk of reoperation, heart failure, need for heart transplantation, complications like atrial fibrillation, and premature death. ${ }^{36}$ Increased risk of premature death is particularly associated with the following CHD patient groups: those having had cyanotic heart disease (especially those with Eisenmenger syndrome [development of pulmonary hypertension leading to shunt reversal and cyanosis]); those with repaired tetralogy of Fallot; those with Fontan palliation procedures for single ventricle; and those with subaortic right ventricles. ${ }^{36}$

Currently, a number of percutaneous and other less invasive techniques for cardiac repair in adults with CHD are increasingly being used. ${ }^{37}$ While this has decreased the number of more invasive surgeries, and increased the quality of life for these patients, longterm outcomes need to be studied. ${ }^{37}$ 


\section{Hirschsprung Disease}

Lastly, the rare congenital condition Hirschsprung disease is generally surgically repaired during the first year of life, and most patients are diagnosed and repaired prior to young adulthood..$^{38}$ Despite successful repair, significant issues remain for adults who had been treated for this condition as children. This includes constipation, fecal or urinary incontinence, repeat surgery, and issues of sexual function. ${ }^{38,39}$ A study of 66 adults with repaired Hirschsprung disease in France observed reports of significant emotional distress and concerns regarding body image, but higher educational levels and similar marital and parental status, as those of the general population. ${ }^{38}$ While sexual function is generally preserved in adults with Hirschsprung disease, sexual distress was a significant issue in adult women and associated with perceived selfcompetence as an adolescent. ${ }^{39}$ Hirschsprung disease has been a significant challenge for patients with DS regarding limitations on their independence due to incontinence. ${ }^{40}$

\section{Improving Clinical Support}

What can we, as clinicians and caregivers, do to help this population? First, we must appreciate the blessing of these individuals living well into adulthood and frequently thriving. Beyond that, we must ensure that there is an adequately trained workforce to care for these adult survivors of serious congenital disease. In some cases, traditional pediatric specialists have been extending their care of these specific populations within their practice well into adulthood. ${ }^{41}$

We must strive to provide appropriate, thoughtful, and informed care of common adult conditions that may have their onset in childhood. This includes promotion of self-management of health conditions, when appropriate. ${ }^{7}$ In addition, we should be attuned to "normal abnormal" laboratory findings in such individuals, as those with DS, in addition to unique adult-onset illnesses such as early Alzheimer's dementia. We must be prepared to provide or refer for appropriate palliative and end-of-life care when the need arises.

Equally important, we need to strive to ensure adequate psychosocial support for these individuals beyond that needed for typical adolescent-to-adult transition. ${ }^{7,38}$ This includes social services and community-based programs and resources as needed, screening for abusive situations, and, particularly in the case of $\mathrm{CF}$, psychological support regarding patients' concerns surrounding a limited life span. ${ }^{31}$ We must inquire of the patient and/or caregivers regarding perceived stigma due to the patient's intellectual or physical disabilities and provide appropriate support. ${ }^{42}$ Advocacy for the patient regarding appropriate work and adult education accommodations is important as well. ${ }^{43}$

As always, we should be the caring, competent, and compassionate caregivers that this population deserves.

\section{Note Added in Proof}

The authors are reflecting on the suffering likely endured by adults with Down syndrome and others with cognitive and physical disabilities during this COVID-19 pandemic. Their isolation may be particularly acute. Day programs, work programs, Special Olympics, and other socially enriching activities are suspended. Grocery store "adventures" may not be done safely. Technology-based social networking from home may be severely restricted due to inherent lack of ability to communicate using these media or older parents not having such technologies in their homes. Some individuals may not have the cognitive ability to understand technical/ logistical aspects of social distancing and mask wearing. They may be scared and confused. For those being hospitalized for COVID-19, this may be the first frightening experience ever of not having a parent or personal caregiver at their side. These patients need our particular attention during these times.

\section{References}

1. Hughes M, Macica C, Meriano C, Doyle M. Giving credence to the experience of X-linked hypophosphatemia in adulthood: an interprofessional mixed-methods study. J Patient Cent Res Rev. 2020;7:176-88.

2. Mubanga N, Baumgardner DJ, Kram JJF. Health care transitions for adolescents and young adults with special health care needs: Where are we now? J Patient Cent Res Rev. 2017;4:90-5. CrossRef

3. Whittemore R, Delvy R, McCarthy MM. The experience of partners of adults with type 1 diabetes: an integrated review. Curr Diabetes Rep. 2018;18:19. CrossRef

4. de Montalembert M, Guitton C; French Reference Centre for Sickle Cell Disease. Transition from paediatric to adult care for patients with sickle cell disease. Br JHaematol. 2014;164:630-5. CrossRef

5. Nicolaidis C, Kripke CC, Raymaker D. Primary care for adults on the autism spectrum. Med Clin North Am. 2014;98:1169-91. CrossRef

6. Vajro P, Ferrante L, Lenta S, Mandato C, Persico M. Management of adults with paediatric-onset chronic liver disease: strategic issues for transition care. Dig Liver Dis. 2014;46:295-301. CrossRef

7. While AE, Heery E, Sheehan AM, Coyne I. Health-related quality of life of young people with long-term illnesses before and after transfer from child to adult health care. Child Care Health Dev. 2016;43:144-51. CrossRef

8. Capone GT, Chicoine B, Bulova P, et al. Co-occurring medical conditions in adults with Down syndrome: a systematic review toward the development of health care guidelines. Am J Med Genet A. 2018;176:116-33. CrossRef 
9. Ross WT, Olsen M. Care of the adult patient with Down syndrome. South Med J. 2014;107:715-21. CrossRef

10. Global Down Syndrome Foundation. Facts and FAQ about Down syndrome. https://www.globaldownsyndrome. org/about-down-syndrome/facts-about-down-syndrome/ Accessed February 6, 2020.

11. Ervin DA, Hennen B, Merrick J, Morad M. Healthcare for persons with intellectual and developmental disability in the community. Front Public Health. 2014;2:83. CrossRef

12. Davidson MA. Primary care for children and adolescents with Down syndrome. Pediatr Clin North Am. 2008;55:1099-111. CrossRef

13. Baum RA, Nash PL, Foster JE, Spader M, Ratliff-Schaub K, Coury DL. Primary care of children and adolescents with Down syndrome: an update. Curr Probl Pediatr Adolesc Health Care. 2008;38:241-61. CrossRef

14. Sobey CG, Judkins CP, Sundararajan V, Phan TG, Drummond GR, Srikanth VK. Risk of major cardiovascular events in people with Down syndrome. PLoS One. 2015;10(9):e137093. CrossRef

15. Lal C, White DR, Joseph JE, van Bakergem K, LaRosa A. Sleep-disordered breathing in Down syndrome. Chest. 2015;147:570-9. CrossRef

16. Mixter S, Stewart RW. Adult head and neck health care needs for individuals with complex chronic conditions of childhood. Med Clin North Am. 2018;102:1055-61. CrossRef

17. Hithersay R, Startin CM, Hamburg S, et al. Association of dementia with mortality among adults with Down syndrome older than 35 years. JAMA Neurol. 2019;76:152-60. CrossRef

18. Nieuwenhuis-Mark RE. Diagnosing Alzheimer's dementia in Down syndrome: problems and possible solutions. Res Dev Disabil. 2009;30:827-38. CrossRef

19. Salehi A, Ashford JW, Mufson EJ. The link between Alzheimer's disease and Down syndrome. A historical perspective. Curr Alzheimer Res. 2016;13:2-6. CrossRef

20. Castro P, Zaman S, Holland A. Alzheimer's disease in people with Down's syndrome: the prospects for and the challenges of developing preventive treatments. J Neurol. 2017;264:804-13. CrossRef

21. Alagoz O, Hajjar A, Chootipongchaivat S, et al. Benefits and harms of mammography screening for women with Down syndrome: a collaborative modeling study. J Gen Intern Med. 2019;34:2374-81. CrossRef

22. Saghazadeh A, Mahmoudi M, Dehghani Ashkezari A, Oliaie Rezaie N, Rezaei N. Systematic review and meta-analysis shows a specific micronutrient profile in people with Down Syndrome: lower blood calcium, selenium and zinc, higher red blood cell copper and zinc, and higher salivary calcium and sodium. PLoS One. 2017;12(4):e0175437. CrossRef

23. Smith DS. Health care management of adults with Down syndrome. Am Fam Physician. 2001;64:1031-8.

24. Chicoine B, Capone G. Regression in adolescents and adults with Down syndrome. In: Prasher VP, Janicki MP (eds). Physical Health of Adults with Intellectual and Developmental Disabilities, Second Edition. Basel, Switzerland: Springer Nature Switzerland AG, 2019, pp. 121-40. CrossRef

25. Mircher C, Cieuta-Walti C, Marey I, et al. Acute regression in young people with Down syndrome. Brain Sci. 2017;7(6):57. CrossRef

26. McGuire D, Chicoine BA, Greenbaum E. "Self-talk" in adults with Down syndrome. Disability Solutions. 1997;2(2):1, 3-5.
27. Kumin L, Schoenbrodt L. Employment in adults with Down syndrome in the United States: results from a national survey. J Appl Res Intellect Disabil. 2016;29:330-45. CrossRef

28. Elborn JS, Bell SC, Madge SL, et al. Report of the European Respiratory Society/European Cystic Fibrosis Society task force on the care of adults with cystic fibrosis. Eur Resp $J$. 2016;47:420-8.

29. Flume PA. Smoothing the transition from pediatric to adult care: lessons learned. Curr Opin Pulm Med. 2009;15:611-4. CrossRef

30. Ramsay KA, Sandhu H, Geake JB, et al. The changing prevalence of pulmonary infection in adults with cystic fibrosis: a longitudinal analysis. J Cyst Fibros. 2017;16:70-7. CrossRef

31. Moola FJ, Norman ME. 'Down the rabbit hole': enhancing the transition process for youth with cystic fibrosis and congenital heart disease by re-imagining the future and time. Child Care Health Dev. 2011;37:841-51. CrossRef

32. Crowley EM, Bosslet GT, Khan B, Ciccarelli M, Brown CD. Impact of social complexity on outcomes in cystic fibrosis after transfer to adult care. Pediatr Pulmonol. 2018;53:735-40. $\underline{\text { CrossRef }}$

33. Sawicki GS, Ostrenga J, Petren K, et al. Risk factors for gaps in care during transfer from pediatric to adult cystic fibrosis programs in the United States. Ann Am Thorac Soc. 2018;15:234-40. CrossRef

34. Philip JA, Gold M, Sutherland S, et al. End-of-life care in adults with cystic fibrosis. J Palliat Med. 2008;11:198-203. CrossRef

35. Cotts TB. Transitions of care in congenital disease: allaying fears for patients and specialists. Prog Cardiovasc Dis. 2018;61:282-6. CrossRef

36. Greutmann M, Tobler D. Changing epidemiology and mortality in adult congenital heart disease: looking into the future. Future Cardiol. 2012;8:171-2. CrossRef

37. Wilson W, Osten M, Benson L, Horlick E. Evolving trends in interventional cardiology: endovascular options for congenital disease in adults. Can J Cardiol. 2014;30:75-86. CrossRef

38. Drissi F, Meurette G, Baayen C, et al. Long-term outcome of Hirschsprung disease: impact on quality of life and social condition at adult age. Dis Colon Rectum. 2019;62:727-32. CrossRef

39. Witvliet MJ, van Gasteren S, van den Hondel D, Hartman E, van Heurn L, van der Steeg A. Predicting sexual problems in young adults with an anorectal malformation or Hirschsprung disease. J Pediatr Surg. 2018;53:1555-9. CrossRef

40. Friedmacher F, Puri P. Hirschsprung's disease associated with Down syndrome: a meta-analysis of incidence, functional outcomes and mortality. Pediatr Surg Int. 2013;29:937-46. CrossRef

41. Durkin ET, Zurakowski D, Rangel SJ, Lillehei CW, Fishman LN. Passing the baton: the pediatric surgical perspective on transition. J Pediatr Surg. 2015;50:1196-200. CrossRef

42. Ali A, Hassiotis A, Strydom A, King M. Self stigma in people with intellectual disabilities and courtesy stigma in family carers: a systematic review. Res Dev Disabil. 2012;33:2122-40. CrossRef

43. National Center for Learning Disabilities. Transitioning to life after high school. Posted 2017 Jan 27. https:/www.ncld.org/ research/state-of-learning-disabilities/transitioning-to-lifeafter-high-school/. Accessed February 11, 2020.

(C) 2020 Aurora Health Care, Inc. 